\title{
Time-Driven Activity-Based Costing for a Library Acquisition Process: A Case Study in a Belgian University
}

Kristof Stouthuysen, Michael Swiggers, Anne-Mie Reheul, Filip Roodhooft

HUB RESEARCH PAPER 2009/25 SEPTEMBER 2009

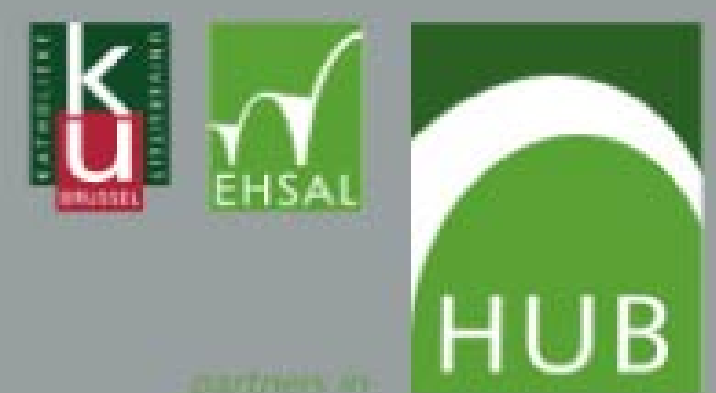


Time-Driven Activity-Based Costing for a Library Acquisition Process:

\section{A Case Study in a Belgian University}

\section{Kristof Stouthuysen ${ }^{1}$}

Hogeschool-Universiteit Brussel \& Katholieke Universiteit Leuven

Stormstraat 2

1000 Brussel - Belgium

E-mail: kristof.stouthuysen@econ.kuleuven.be

Telephone: +32 498089711

\section{Michael Swiggers}

Hogeschool-Universiteit Brussel, Stormstraat 2, 1000 Brussel - Belgium

\section{Anne-Mie Reheul}

Hogeschool-Universiteit Brussel, Stormstraat 2, 1000 Brussel - Belgium

\section{Filip Roodhooft}

Katholieke Universiteit Leuven \& Vlerick Leuven Gent Management School, Naamsestraat 69, 3000 Leuven - Belgium 


\title{
Time-Driven Activity-Based Costing for a Library Acquisition Process:
}

\section{A Case Study in a Belgian University}

\begin{abstract}
Library managers are continuously urged to provide better library services at a lower cost. To cope with these cost pressures, library management needs to improve its understanding of the relevant cost drivers. Through a case study, we show how to perform time-driven activity-based costing for a library acquisition process in a Belgian university and provide evidence of the benefits of such an analysis.
\end{abstract}

Keywords: Time-driven activity-based costing; Cost control; Acquisition process; Academic library 


\section{Introduction}

One of the main challenges of academic libraries is providing qualitative library services at continuously diminishing costs. As many library services are free of charge, academic libraries heavily rely on government funding. However, government funding does not cover increasing library costs (Ellis-Newman \& Robinson, 1998) [1]. To keep costs under control it is important for library management to gain insight into the relevant cost drivers. Recently, libraries have started to invest in more sophisticated cost-accounting systems, such as activity-based costing (ABC) (see, for example, Ellis-Newman \& Robinson, 1998, 2003; Goddard \& Ooi, 1998; Ching et al., (2008) [1-4]. ABC is an advanced cost calculation technique that allocates resource costs to products based on resource consumption. Since $\mathrm{ABC}$ may provide greater visibility into organizational processes and their cost drivers, researchers have claimed that $\mathrm{ABC}$ allows library managers to better control costs, for example by eliminating costs related to non-value adding activities (Ellis-Newman \& Robinson, 1998, 2003) [1-2].

While several articles have advocated the use of $\mathrm{ABC}$ by service organizations in general and academic libraries in particular (Ellis-Newman \& Robinson, 1998, 2003; Goddard \& Ooi, 1998; Ching et al., 2008) [1-4], there is, nevertheless, need for some degree of caution. Kaplan \& Anderson (2004, 2007) [5-6], for example, note that the procedure for estimating an ABC model has proved to be difficult and costly, especially if the current accounting system does not support the collection of $\mathrm{ABC}$ information. Also updating the $\mathrm{ABC}$ model through a new round of interviews and surveys has been argued to further increase its time and resource consumption (Kaplan \& Anderson, 2007) [6]. As a result, Pernot et al. (2007) [7] claim that many managers who have tried to implement ABC in their organizations, including library managers, have abandoned the attempt in the face of rising costs and employee irritation.

In order to overcome the difficulties of ABC, Kaplan \& Anderson (2004, 2007) [5-6] developed a new approach to ABC, called time-driven ABC (TDABC). Accordingly, a TDABC model is simpler and faster to implement as it requires estimates of only two parameters: (1) the unit 
cost of supplying capacity and (2) the time required to perform a transaction or an activity. The breakthrough of TDABC lies in the usage of time equations to estimate the time spent on each activity (Demeere et al., 2009) [8]. Through the inclusion of multiple time drivers, a time-driven approach to $\mathrm{ABC}$ can capture the complexities of organizational processes far more simply than the traditional ABC system. After all, the latter would have to account for varying transaction times by treating each variant of the process as a distinct activity, which significantly increases its complexity (Cooper \& Kaplan, 1988; Kaplan \& Anderson, 2007; Everaert et al., 2008) [8-10]. Hence, TDABC seemingly provides many opportunities to design manageable cost models in environments with complex activities as in academic libraries and service organizations in general.

This paper describes the development and application of a TDABC system for an academic library in a Belgian University. Although we argue that TDABC may improve the cost management of several library processes, in this study we only focus on the "acquisition” process. A major reason for this is that the process of obtaining materials for academic libraries is more complex than ever. According to Schmidt (1999) [11], academic libraries have witnessed dramatically reduced budgets while the materials that academic libraries need have broadened immensely. For example, library staff must address issues of electronic publishing, automated communications with vendors and new producers of library materials. Indeed, Pernot et al. (2007) [7] note (p.559) that "performing a TDABC analysis on the acquisition activity will be highly useful as the activity is complex, time consuming and diverse". Therefore, the acquisition process offers an attractive context for this study.

The remainder of this paper is organized as follows. In Section 2 we briefly address the technique of TDABC. In Section 3 we present the TDABC academic library case. In Section 4 we describe how the TDABC information guided library management in streamlining the acquisition process. We end with concluding remarks in Section 5.

\section{Theoretical background: from ABC to TDABC}


$\mathrm{ABC}$ has proven to be a valuable tool in service organizations such as academic libraries (Ellis-Newman \& Robinson, 1998, 2003; Goddard \& Ooi, 1998; Ching et al., 2008) [1-4]. It helps understanding cost drivers and identifying non-value adding activities and services or processes consuming more resources than average. The core idea behind ABC is that cost objects (e.g. products, customers) consume activities which in turn consume resources (e.g. wages, equipment) (Demeere et al., 2009) [8]. The assignment of overhead costs occurs in 2 corresponding stages. In the first stage, resources are allocated to activities using resource cost drivers. For example, wages are allocated to the activity "ordering" using "the amount of books received" as a resource cost driver. In the second stage, the cost of activities is allocated to the cost objects using activity cost drivers, which measure the demands a cost object places on an activity. The process of an ABC model typically follows the steps outlined in Table 1, panel A.

$<<$ Insert Table 1 about here $>>$

While traditional cost-accounting systems allocate overhead costs using a single volume-based ratio, the $\mathrm{ABC}$ model achieves improved accuracy in the estimation of costs by using multiple cost drivers (Everaert et al., 2008) [12]. Additionally, the produced ABC information assists library management in their monitoring and decision-making activities and makes it more likely for managerial recommendations concerning amelioration opportunities (Pernot et al., 2007; Ching et al., 2008) [4,7].

Although the studies above found ABC providing library management with a more detailed cost analysis and important cost- and value-enhancement opportunities, in practice ABC models are not easy to implement and several limitations exist. A first limitation implies the time and cost demands associated with the development of ABC (Kaplan \& Anderson, 2004, 2007) [5-6]. To build a traditional ABC model, you would survey employees to estimate the percentage of time they spend (or expect to spend) on the different activities and then assign the department's resource expenses according to the average percentage you get from your survey (Kaplan \& Anderson, 2007; 
Demeere et al., 2009) [6,8]. While this approach works well in a limited setting, it becomes quite complicated in large organizations or in the case of many (small varying) activities. A second limitation is that the ABC system needs to be regularly updated, which further increases its cost (in time and resources). As a result, Pernot et al. (2007) [7] note that many ABC systems will remain in their original form, becoming increasingly useless over time and providing increasingly wrong managerial information. A third drawback is that the ABC model builds on subjective information, mainly procured by employees. Apart from measurement error, employees might behave differently, or give wrong or socially desirable answers. This response bias can greatly distort the data and therefore the ABC model's accuracy has been called into question many times (Schmidt, 1999; Everaert et al., 2008) [10,12]. As a result, managers might argue about the model's accuracy, rather than dealing with the inefficiencies and possible process-improvements revealed by the model. A fourth limitation is that $\mathrm{ABC}$ uses a single driver rate. In traditional ABC models the cost of an activity is driven by one activity cost driver. In reality, however, many activities are often driven by more than one activity driver. For example, consider the activity 'ordering books'. Following a traditional ABC approach, you might use 'number of ordered books' as an activity driver. To obtain the ordering cost of one book, you would then need to divide the resource costs allocated to the activity 'ordering books' by the number of ordered books. As a result, this procedure assigns an equal cost to each book order. A book’s ordering cost, however, may also depend on other factors, such as whether the book order concerns a 'known' or an 'unknown' book. In theory, it would then be a solution to split the activity into two sub-activities 'ordering known books' and 'ordering unknown books', and respectively use as activity drivers 'number of known book orders' and 'number of unknown book orders'. In practice, however, splitting inflates the number of activities in $\mathrm{ABC}$ and creates difficulties in estimating the practical capacity for each sub-activity.

The solution to the problems with $\mathrm{ABC}$ is not to abandon the concept. Instead, Kaplan \& Anderson (2004) [5-6] developed an improved approach to ABC, the TDABC approach. As with 
the traditional $\mathrm{ABC}$ approach, the new procedure starts with estimating the cost of supplying capacity. The TDABC approach identifies the different departments, their costs and their practical capacity. For library operations, the practical capacity is expressed as the amount of time that employees can work, without idle time. Often practical capacity is estimated as a percentage, say $80 \%$ or $85 \%$, of theoretical capacity (Kaplan \& Anderson, 2004; Demeere et al., 2009) [5,8]. By dividing the total cost by the practical capacity, the cost per time unit is calculated. Costs then are assigned to the cost object by multiplying the cost per time unit by the time needed to perform the activity, as shown in Panel B of Table 1.

The breakthrough of TDABC lies in the time estimation and its usage of time equations. The TDABC model relies on the absolute time duration spent on each activity, rather than on a percentual time allocation. So, not the percentage of time spent on ordering books is measured, but the time duration spent on ordering 1 book. After all, not every book is ordered in the same way. The time (and thus the cost) to order a book depends on many factors. To cope with this complexity, the time-driven approach uses the method of time equations. These time equations model how different time drivers (i.e. case-specific characteristics) drive the time spent on activity. In complex environments where the time needed to perform an activity is driven by many drivers, TDABC can include multiple drivers for each activity. As such, time equations greatly simplify the estimation process and produce a far more accurate cost model than would be possible using traditional $\mathrm{ABC}$ techniques. Consequently, in complex environments, TDABC allows managers to develop accurate cost models that remain manageable in terms of implementation and maintenance efforts (Evereart et al., 2008) [12].

Consider again the example of ordering books. In a TDABC model the difference between a known versus an unknown book order is taken into account by integrating it in the time equation of the 'ordering a book' activity, rather than by distinguishing between two (sub-) activities. Now, assume that empirical measurements reveal that ordering a book demands 2 minutes, and that 
looking up necessary information for an unknown book takes an additional 2 minutes. The time equation for this example would be as follows:

Time (in minutes) for 'ordering a book' $=2+2$ If further information is required

Once a TDABC system is in place, department heads can review the cost of the unused capacity and contemplate actions to determine whether and how to reduce costs of supplying unused resources in subsequent periods: they can then monitor those actions over time (Demeere et al. 2009) [8]. Also a TDABC model can be kept up-to-date with a minimum of effort. That is, to add a new activity only the time duration to perform this activity needs to be measured and included in the model (Kaplan \& Anderson, 2004, 2007) [5,6]. In the following section, we describe the time estimation procedure and the managerial impact of a TDABC model in an academic library.

\section{TDABC in an academic library}

\subsection{Research setting and data gathering process}

The academic library under study is situated in Belgium. It is part of a larger association of universities and university colleges, but is managed with local autonomy. Library staff consists of approximately 7 fulltime equivalent employees and is responsible for various tasks: reception, administrative support and library management. We make a distinction between a category A (i.e., library management), B (i.e., administrative support) or C (i.e., reception) employee based on his wage scale.

In this article, we focus on the library acquisition process. That is, the process of acquiring new items for the library, which involves the decision to purchase or not, the choice of the supplier, and the administration regarding the full process. The cost objects in this study are the items purchased. We make a distinction between foreign books, local books, grey literature, and the rest. This distinction allows us to derive comparative cost structure data for the 4 cost objects. 
Relevant activity data were identified through direct observation and multiple interviews with both administrative employees and library management. Cost data were obtained from the university's financial and human resources managers. In order to derive the time equations for the TDABC model, we needed estimates of the required time to perform one activity. For that reason, we registered by stopwatch the different time consumptions for all relevant activities. Registration of the times was done during 3 days in February 2009. In order to obtain consistent results, new time registrations were performed 2 months later. Comparing the results of both periods, we found no statistically different results.

\subsection{Developing the TDABC model}

In this part of the paper, we construct the time-driven ABC model for the acquisition process of the academic library. First, the activity flow of the acquisition process is identified and time equations are constructed for each relevant activity. Second, the related library costs are identified and the cost per time unit of the different activities is calculated. Third, using the time equations and the cost per time unit, the cost of 4 different items purchased by the library (the cost objects) is calculated.

\subsubsection{Activity analysis and time equations}

In order to construct the time equations, the relevant activities comprising the acquisition process need to be identified. By means of interviews it was revealed that the acquisition process can be subdivided into 5 activities, which are shown in Figure 1.

$<<$ Insert Figure 1 about here $>>$

In a first step, library staff notifies university professors and researchers of new, relevant books or papers. As library employees are often well connected to publishers, they receive many folders and other information about newly published items. If the library judges these items to be relevant, 
professors and researchers are notified of it $^{2}$. The second activity involves processing the purchase requests. Requests can result from information given by the library or can emanate from the researcher himself. In the latter case, the library examines the item's added value to the collection and decides whether to purchase it or not. Sometimes, the library inquires for more information. Finally, the person who requested the specific item is informed about the library's decision. If the library's decision is in favor of ordering the item, the order is placed. This is the third activity. This activity is responsible for the main differences between the 4 cost objects since they are all procured using different methods. Local books are ordered through book stores. Foreign books are ordered through an online supplier. Journals are ordered trough a web-based intermediary. The remaining items, mainly grey literature like research papers published by educational institutions or other non-profit organizations, are ordered at the institution publishing it. The fourth activity consists of processing the invoice. Finally, the fifth activity closes the acquisition process by informing the person who requested the item on its arrival.

The activities are comprised of several actions. Some of the actions are standard; others are optional or situation-specific. To allow for this difference in the time equations optional actions are represented by dummy variables (Table 2). The dummy is 0 when the optional action is not used in the particular case, it is 1 when the optional action takes place and its time has to be taken into account. The total time in minutes is the sum of the standard and optional actions. All the activities are chronological, making it easier to follow the flow. Sometimes small activities are taken together if they occur together and their cost per time unit is the same. Table 2 presents the time equations of the 5 activities comprising the acquisition process.

$<<$ Insert Table 2 about here $>>$

To get an idea of the method of working, the discussion below is restricted to the acquisition process for local books.

\footnotetext{
${ }^{2}$ Similar to the library staff, professors and researchers are also well informed about interesting library items. As such, professors and researchers may
} also suggest by themselves items that are interesting for the library to acquire. When this is the case, they will notify the library personnel. 


\section{Notifying}

Information about newly published items is received by the library in digital or in paper form. Digital information refers to e-mails or links to publishers' websites. Information on paper refers to folders or booklets sent by publishers or bookstores. Digital information takes 0.49 minutes to read. If deemed necessary, the library performs additional checks like referring to the Internet for further information or making sure the item is not in collection already. These optional checks require 0.51 minutes. If the item passes the checks, researchers and professors related to the topic are informed by mail, which takes 0.98 minutes. When the library receives the information in paper form, reading it takes 0.48 minutes. Like with digital information, possible additional checks take 0.51 minutes. If the item passes the checks, the paper information is stamped and approved for forwarding to professors and researchers. Stamping and approval demand 0.24 minutes. Finally, the information is taken to the internal mailing system for distribution, taking another 1.74 minutes per item. This final step is handled by a category $\mathrm{C}$ employee. All previous steps are handled by a category A employee. Based on this notification professors and researchers decide whether or not to request the item. If not, then the process ends here.

\section{Processing the request}

Requests to the library happen digitally. It requires 0.94 minutes to read and reply a request. If the request concerns an item not suggested by the library itself, additional information needs to be gathered, which consumes 0.51 minutes. Further, it is possible that missing information such as the item's edition needs to be retrieved from the person making the request. Also when a request concerns a specific item suggested by a professor or a researcher, additional approval is obtained from a senior professor who is familiar with the requested item and its relevance. In each case, an email needs to be sent, and a reply needs to be read. As sending and reading an email consumes 0.94 minutes, like in the first step, retrieving missing information takes 0.94 minutes and obtaining additional approval as well. Finally, the request, accompanied by the necessary information and 
approvals, is forwarded to the person responsible for placing the order. Forwarding the request consumes 0.88 minutes. The actions to process a request are executed by a category A employee.

\section{Placing the order}

Placing an order requires a standard time of 0.24 minutes, performed by a category B employee. This is the time required for grouping the orders by category and filing them afterwards. If the order needs further investigation, this takes an additional 0.51 minutes. Further, the inputting procedure differs for the 4 different items (local books, foreign books, journals and the rest). Unlike foreign books, journals and the rest, which are ordered through intermediaries or web-based stores, local books are ordered using a specific software program. The ordering process involves 4 actions. The first action concerns a category B employee processing the order manually. This requires 1.31 minutes. Then, both a category A and B employee have to log in to the ordering software, which takes 0.98 minutes for each employee. Next, a category B employee processes the order, using the ordering software. This action demands 2.76 minutes. The fourth action involves a category A employee, head of the department, approving the order in the software, which requires 0.26 minutes. These four actions are not added together because they each have a different cost per minute. Unlike foreign books, journals and the rest, the ordering method of local books does not rely on an internal database. Consequently, if some parts of information on the local book are still missing (e.g. ISBN number, publisher) these are not added automatically by the software, but need to be searched and added by a category B employee, taking another 1.69 minutes.

\section{Processing invoice}

Approving an invoice requires 0.49 minutes of a category A employee. To further process the invoice a category B employee needs a standard time of 0.28 minutes. If the provider did not include a copy, the category B employee makes one, taking 0.14 minutes on average. Next, specifically for local books, several actions take place. In a first step, a category B employee checks 
whether the invoice matches the order, checks the ISBN number, assigns an invoice number and adds internal references. These actions take 1.21 minutes. In a second step, a category A employee logs in to the ordering software, composes a delivery note and puts in the invoice. The fist action demands 0.98 minutes, the two latter actions require 1.24 minutes

\section{Process closing}

Finally, the person who requested the book is informed about its arrival by means of an email. It takes 1.47 minutes to send this email. However, sometimes more information needs to be included in the mail, which further increases its time consumption with 0.23 minutes. These actions are all performed by a category $\mathrm{C}$ employee.

\subsubsection{Identifying cost per minute}

In this stage we calculate the cost per time unit, mostly minutes, spent on an activity. All cost rates are measured using practical capacity rather than theoretical capacity. As mentioned above, the practical capacity is taken at $80 \%$ of the theoretical capacity. This is a generally agreed upon number in the management accounting literature (Kaplan \& Anderson, 2004; Cooper \& Kaplan, 1988) $[5,10]$. The acquisition process of library items is mainly labor-intensive and hardly demands any specific equipment. The costs associated with the acquisition process are mainly comprised of the wages of the employees involved and overhead costs. In addition, for the purchase of local books, the library makes use of a specific software program, a specific cost which is added separately.

With regard to the cost of wages, 3 different employee categories are distinguished: A, B and C. The wage cost of an employee consists of the gross yearly wage increased with costs such as social security. For a category A employee the yearly wage cost is $€ 81,054$, for a category B

employee $€ 39,485$ and for a category $C$ employee $€ 32,440$. Next, there are 3 types of overhead 
costs: overhead personnel ( $€ 2,728,856$ on a yearly basis), general overhead ( $€ 5,067,925$ on a yearly basis), and the usage of telephone and computer ( $€ 963$ on a yearly basis).

To obtain the fully loaded staff labor cost per minute, we first calculate the wage cost per time unit. Therefore, we divide the yearly wage cost by the practical capacity. As the practical capacity equals 80,256 minutes per person per year ( $80 \%$ x (220 working days x 7.6 hours per day)), the wage cost per minute for a category A employee equals $€ 1.01$, for a category B employee $€ 0.49$ and for a category $C$ employee $€ 0.40$. In a similar vein, we do this for the overhead personnel. To this end, we first multiply the wage cost per minute by a ratio of $12.08 \%$ ( $€$ $2,728,856$ / € 22,586,867). This ratio reflects the percentage of overhead personnel compared to the global wage cost. The overhead personnel cost per minute for a category A employee is then $€$ 0.12, for a category B employee $€ 0.06$ and for a category $C$ employee $€ 0.05$. As mentioned before, the general overhead amounts $€ 5,067,925$ on a yearly base. As the total amount of surface equals $21,049 \mathrm{~m}^{2}$, the cost per square meter is $€ 240$. As each library employee occupies (on average) 11 square meter of surface, general overhead per employee amounts $€ 2,880$. Reckoning with the practical capacity, the cost per minute is then $€ 0.03$. The usage of telephone and computer equals $€$ 0.012 per minute per employee ( $€ 963$ / 80,256 minutes). Based on these separate cost rates, Table 3 reports the fully loaded staff labor cost per minute (i.e., $€ 1.17$ for employee A, $€ 0.592$ for employee B, € 0.492 for employee C).

$<<$ Insert Table 3 about here $>>$

Finally, specifically for ordering local books, the library makes use of a specific software program. According to the library manager, the yearly cost of this program equals $€ 1,234$ for the library. On the base of historical data, it was calculated that on average the university library ordered 616 local items per year. Hereby, registration times suggested it took 4.26 minutes for entering one order (with the specific software), leading to a total capacity of 2,642.16 minutes per year. The specific software cost per minute for local books is then $€ 0.47$. 


\subsubsection{Calculating the cost of the items' acquisition process}

In this stage we calculate the cost of the acquisition process for the different library items. To this end, we multiply the time duration of each action, presented in the time equations in Table 2, with the cost per time unit, presented in Table 3. We will calculate a minimum and a maximum cost price, based on the distinction between standard and optional actions.

First, we consider the actions comprising the notifying activity. Not every item that is ordered in the end, results from a suggestion from the library. If this is the case, the cost of the notifying activity cannot be attributed to the item. To take variations in the acquisition process into account, a separate cost object is created: 'items suggested by the library' is created. Table 4 reveals that the latter cost object costs $€ 2.321$ at most if the library was informed digitally, and $€$ 2.298 if the library was informed in paper form. If, however, the optional checks are not performed, the cost decreases with $€ 0.598$, both in the case of digital and paper information. Minimally, the notifying activity consists of reading the digital or paper information, without further actions. Consequently, this activity costs at least $€ 0.574$ in the case of digital information and $€ 0.563$ in the case of paper information.

$<<$ Insert Table 4 about here $>>$

In Table 5 and 6 we present the cost data of the 4 subsequent activities: processing the request, placing the order, processing the invoice and closing the process. Some actions, which are optional in theory, are assumed to be standard in Tables 5 and 6 because we want to calculate the minimum and maximum cost of an acquisition process that passes through each of the 4 subsequent stages and eventually results in the acquisition of the item.

$<<$ Insert Table 5 about here $>>$

$<<$ Insert Table 6 about here $>>$ 
The 4 items demonstrate large variations in cost price, whereas they seem quite similar. The standard cost is $€ 5.443$ for foreign books, $€ 14.692$ for local books, $€ 5.36$ for journals and $€ 7.48$ for the rest. These variations can be attributed to differences in the acquisition process. Both journals and foreign books are less costly because the acquisition process is simple and fast. All journals are bought via the same intermediary and all foreign books via the same online bookstore. For local books, however, a complicated software program is used, which causes many additional activities. Also the rest category is rather expensive because these items cannot be ordered in the regular circuit and consequently demand more research concerning where and how these items can be found. With regard to the optional costs there are fewer variations. Optional costs for foreign books, journals and the rest amount to $€ 3.3$ and for local books to $€ 4$.3. The maximum cost is thus $€ 8.743$ for foreign books, $€ 18.992$ for local books, $€ 8.66$ for journals and $€ 10.78$ for the rest category. In the next section, we will clarify these differences.

As stated earlier, in this paper cost objects are individual books or items. However, sometimes when placing an order or receiving an invoice, multiple items are handled simultaneously. For example, the library orders 3 books at the same time and it receives one invoice for these books. In order to allocate this cost correctly to the individual items, we gathered data on the average amount of books ordered simultaneously, and on the average amount of books on the same invoice. By dividing the time required for processing an invoice by the average amount of books on an invoice, and by dividing the time for ordering a book by the average amount of books ordered simultaneously, we obtained the time durations and costs per book.

\section{The benefits of TDABC: Some managerial implications}

The implementation of the TDABC model revealed much about the acquisition process. Using this TDABC information, library management was able to identify several factors that drive the cost of the acquisition process of library items. In the next paragraphs, we discuss these factors 
and present actions that library management has taken or could take to optimize the acquisition process.

Firstly, the TDABC model indicated that the acquisition of local books was far more expensive than the acquisition of other items due to the use of specific purchasing software. Table 5 reveals that placing an order and processing an invoice through the software program takes much more time and thus increases the cost price of local books considerably. This is for example because the program requires multiple user confirmations of one person for the same transaction, and because the program does not contain a database module, implying that library personnel itself has to fill in missing supplier data. As such, the software package did not meet the specific and practical needs of the library personnel as it was a package for general use, employed by other departments of the university as well. Based on the results of this research and the recognition of the software's inefficiency, library management decided to purchase a new, library-specific software program. This program offered the possibilities to build a database and to provide digital signatures, which resembles the less costly method used for acquiring journals and foreign books.

Secondly, TDABC information revealed that pooling of activities could lead to substantive time and cost savings. Many actions could be combined: orders could be placed for multiple items at a time, suppliers could be persuaded to pool ordered books in a single invoice, copies could be made for more than one invoice at the time, etc. Pooling tasks at certain moments in the week could avoid a lot of unnecessary processing time. Though, it would also go together with a delay in the acquisition process. This, however, is rarely a problem. Moreover, it would still be possible to accept priority orders that are processed ahead of the scheduled time. Pooling was already applied on a small scale in the library as library personnel considered it advantageous on an intuitive basis. As a consequence of this study’s results, library management decided to expand this method.

Finally, TDABC cost information demonstrated that costs increase considerably if category A personnel is involved in the acquisition process. The library employs three categories of employees, each having a different wage. From a cost perspective it is advisable to involve many 
low-wage employees in the process, as long as they are capable of the tasks. About $50 \%$ of the costs could be saved if a category B employee would handle the "notification" activity. A downside would be that the category A employee, the head of department, is not informed anymore about the items suggested to the professors. This might result in the acquisition of items that the head of department does not consider to be an added value to the collection. This drawback, however, might well be worth the cost savings. When implementing the new software system, the library plans to further streamline the process by re-allocating staff to specific tasks.

\section{Conclusion}

In this article we described the implementation and the relevance of a TDABC model in an academic library. TDABC is well suited for a library setting, involving many activities with complex time drivers. Library personnel willingly participated in the time measurements. The obtained model structure was clear and understandable and the implementation went smoothly. Eventually, library personnel welcomed the feedback on their performance and the chance to further improve the process.

The TDABC model was set up for calculating the cost of the acquisition process of 4 kinds of information carriers: foreign books, local books, journals and the rest. The model calculates the minimum and maximum cost of the acquisition process of 4 items, depending on the occurrence of a number of optional actions. The TDABC analysis provided library management with a better insight into the cost drivers of the acquisition process and guided decisions concerning process improvements. On the basis of the cost data, library management decided to replace the general purchasing software with a new software program tailored to the needs of the library. Further, library management took actions regarding pooling of activities and re-allocation of tasks to lowwage personnel.

This research focused on one part of the library's range of activities. A potential avenue for future research is to expand the study to other library activities, such as the cataloguing process. 
Another interesting avenue is doing similar research in different libraries in order to construct a framework for further analysis. 


\section{References}

[1] Ellis-Newman, J., Robinson, P. (1998). The Cost of Library Services: Activity-Based Costing in an Australian Academic Library. Journal of Academic Librarianship, 24 (5), 373-79.

[2] Ellis-Newman, J. (2003). Activity-Based Costing in User Services of an Academic Library. Library Trends, 51 (1), 333-48.

[3] Goddard, A., Ooi, K. (1998). Activity-Based Costing and Central Overhead Cost Allocation in Universities: A Case Study. Public Money and Management, 18 (3), 31-8.

[4] Ching, S., Leung, M., Fidow, M., Huang, K. (2008). Allocating costs in the business operation of library consortium: The case study of Super e-book consortium. Library Collections, Acquisitions and Technical Services, 32 (2), 97-103.

[5] Kaplan, R., Anderson, S. (2004). Time-Driven Activity-Based Costing. Harvard Business Review, 82 (11), 131-8.

[6] Kaplan, R., Anderson, S. (2007). The innovation of time-driven activity-based costing. Journal of Cost Management, 21 (2), 5-15.

[7] Pernot, E., Roodhooft, F., Van den Abbeele, A. (2007) Time-Driven Activity-Based Costing for Inter-Library ervices: A Case Study in a University. Journal of Academic Librarianship, 33 (5), 551-60.

[8] Demeere, N, Stouthuysen, K., Roodhooft, F. Time-Driven Activity Based Costing in an outpatient clinic environment: development, relevance \& managerial impact. Health Policy, 9, 296-304.

[9] Everaert, P., Bruggeman, W., De Creus, C. (2008). Sanac inc.: from ABC to time-driven ABC (TDABC) - an instructional case. Journal of Accounting Education, 26 (3), 118-54.

[10] Cooper, R., Kaplan, R. (1988). Measure costs right, make the right decisions. Harvard Business Review, 66 (5), 96-103.

[11] Schmidt, K (1999). Understanding the Business of Library Acquisitions. Chicago, IL: American Library Association. 
[12] Everaert, P., Bruggeman, W., Sarens, G., Anderson, S R. Levant, Y. (2008). Cost modeling in logistics using time-driven ABC. Experiences from a wholesaler. International Journal of Physical Distribution \& Logistics Management, 38 (3), 158-61. 


\section{Tables}

\section{Table 1}

Activity Based Costing versus Time-Driven Activity-Based Costing (Source: Everaert et al., 2008)

\section{Panel A: ABC}

Step $1 \quad$ Identify the different overhead activities

Step 2 Assign the overhead costs to the different activities using a resource driver

Step 3 Identify the activity driver for ach activity

Step $4 \quad$ Determine the activity driver rate by dividing the total activity costs by the practical volume of the activity driver

Step 5 Multiply the activity driver rate by the activity driver consumption to trace costs to orders, products or customers

Panel B: TDABC

Step 1

Identify the various resource groups (departments)

Step 2

Estimate the total cost of each resource group

Step 3

Estimate the practical capacity of each resource group (e.g. available working hours, excluding vacation, meeting and training hours)

Step $4 \quad$ Calculate the unit cost of each resource group by dividing the total cost of the resource group by the practical capacity

Step 5 Determine the time estimation for each event, based upon the time equation for the activity and the characteristics of the event 
Table 2

Time equations for the acquisition process in an academic library

\begin{tabular}{|c|c|}
\hline Notifying & $\begin{array}{l}(0,49+0,51 \times \text { checks }+0,98 \times \text { mail }) \times \text { digital info }+(0,48+0,51 \times \text { checks }+0,24 \times \text { approval } \\
+1,74 \times \text { delivery }) \times \text { paper info }\end{array}$ \\
\hline Processing request & $\begin{array}{l}0,94+0,51 \times \text { no library suggestion }+0,94 \times \text { retrieval of missing information }+0.94 \times \\
\text { additional approval }+0,88 \times \text { forwarding for order }\end{array}$ \\
\hline Placing order & $\begin{array}{l}0,24+0,51 \times \text { further investigations } \\
+(0,62+1,05) \times \text { foreign book order } \\
+(0,98+0.98+1,31+2.76+0,26+1,69 \times \text { filling in additional info }) \times \text { local book order } \\
+(0,4+1,62) \times \text { journal order } \\
+(5,04) \times \text { rest category order }\end{array}$ \\
\hline Processing invoice & $\begin{array}{l}0,49+0,28+0,14 \times \text { copy } \\
+(1,21) \times \text { foreign book invoice } \\
+\left(1,21+1,24+0,98 \times \text { login }{ }_{l o c a l}\right) \times \text { local book invoice } \\
+(0,72) \times \text { journal invoice } \\
+(1,28) \times \text { rest category invoice }\end{array}$ \\
\hline Process closing & $1,47+0,23 \mathrm{x}$ extra information \\
\hline
\end{tabular}


Table 3

Total cost per minute for the different employee categories

\begin{tabular}{|l|l|l|l|}
\hline & Category A & Category B & Category C \\
& Head of department & Administrative assistant & Reception assistant \\
\hline Yearly cost per minute $(€)$ & $\mathbf{1 . 1 7 2}^{\mathbf{a}}$ & $\mathbf{0 . 5 9 2}$ & $\mathbf{0 . 4 9 2}^{\mathbf{C}}$ \\
\hline
\end{tabular}

$$
\begin{aligned}
& { }^{a}=1.01+0.12+0.03+0.012 \\
& { }^{b}=0.49+0.06+0.03+0.012 \\
& { }^{c}=0.4+0.05+0.03+0.012
\end{aligned}
$$


Table 4

Total cost of the notification activity

\begin{tabular}{|c|c|c|c|c|c|c|c|c|}
\hline & \multicolumn{4}{|c|}{ Digital information } & \multicolumn{4}{|c|}{ Paper information } \\
\hline & Activity & Minutes & $\begin{array}{l}\text { Cost (€)/ } \\
\text { minute }\end{array}$ & Cost $(€)$ & Activity & Minutes & $\begin{array}{l}\text { Cost }(€) / \\
\text { minute }\end{array}$ & Cost (€) \\
\hline \multirow{2}{*}{$\begin{array}{l}\text { Standard } \\
\text { activity }\end{array}$} & Reading info & 0.49 & 1.172 & 0.574 & Reading info & 0.48 & 1.172 & 0.563 \\
\hline & Subtotal & & & 0.574 & Subtotal & & & 0.563 \\
\hline \multirow{5}{*}{$\begin{array}{l}\text { Optional } \\
\text { activity }\end{array}$} & Checks & 0.51 & 1.172 & 0.598 & Checks & 0.51 & 1.172 & 0.598 \\
\hline & Mail & 0.98 & 1.172 & 1.149 & Approval & 0.24 & 1.172 & 0.281 \\
\hline & & & & & Delivery & 1.74 & 0.492 & 0.856 \\
\hline & Subtotal & & & 1.746 & Subtotal & & & 0.856 \\
\hline & Total & & & 2.321 & Total & & & 2.298 \\
\hline
\end{tabular}




\section{Table 5}

Total cost of acquisition of foreign and local books (excluding the notification activity costs)

\begin{tabular}{|c|c|c|c|c|c|c|c|c|}
\hline \multirow{2}{*}{\multicolumn{2}{|c|}{ STANDARD ACTIONS }} & \multicolumn{3}{|c|}{ Foreign books } & & \multicolumn{3}{|c|}{ Local books } \\
\hline & & \multirow{2}{*}{$\begin{array}{l}\begin{array}{l}\boldsymbol{n}^{\circ} \text { of } \\
\text { minutes }\end{array} \\
0.94\end{array}$} & \multirow{2}{*}{$\begin{array}{l}\begin{array}{l}\text { cost }(€) / \\
\text { minute }\end{array} \\
1.172\end{array}$} & \multicolumn{2}{|c|}{$\begin{array}{l}\text { total cost } \\
(€)\end{array}$} & \multirow{2}{*}{$\begin{array}{l}\begin{array}{l}\boldsymbol{n}^{\circ} \text { of } \\
\text { minutes }\end{array} \\
0.94\end{array}$} & \multirow{2}{*}{$\begin{array}{l}\begin{array}{l}\text { cost }(€) / \\
\text { minute }\end{array} \\
1.172\end{array}$} & \multirow{2}{*}{$\begin{array}{l}\begin{array}{l}\text { total cost } \\
(€)\end{array} \\
1.102\end{array}$} \\
\hline Process request & process request & & & 1.102 & process request & & & \\
\hline & forward for order & 0.88 & 1.172 & 1.031 & forward for order & & 1.172 & 1.031 \\
\hline \multirow[t]{5}{*}{ Place order } & place order & $1.29^{\mathrm{a}}$ & 0.592 & 0.764 & place order manually & $1.55^{\mathrm{b}}$ & 0.592 & 0.776 \\
\hline & $\operatorname{login}$ & 0.62 & 0.592 & 0.367 & login cat. B (software) & 0.98 & $1.062^{\mathrm{c}}$ & 1.041 \\
\hline & & & & & login cat. A (software) & 0.98 & $1.642^{\mathrm{d}}$ & 1.609 \\
\hline & & & & & place order (software) & 2.76 & $1.062^{\mathrm{c}}$ & 2.931 \\
\hline & & & & & approve order (software) & 0.26 & $1.642^{\mathrm{d}}$ & 0.427 \\
\hline \multirow[t]{4}{*}{ Process invoice } & approve invoice & 0.49 & 1.172 & 0.574 & approve invoice & 0.49 & 1.172 & 0.574 \\
\hline & process invoice & $1.49^{\mathrm{e}}$ & 0.592 & 0.882 & process invoice & $1.49^{\mathrm{e}}$ & 0.592 & 0.882 \\
\hline & & & & & login (software) & 0.98 & $1.642^{\mathrm{d}}$ & 1.609 \\
\hline & & & & & close invoice (software) & 1.21 & $1.642^{\mathrm{d}}$ & 1.987 \\
\hline Close process & & 1.47 & 0.492 & 0.723 & & 1.47 & 0.492 & 0.723 \\
\hline
\end{tabular}

\begin{tabular}{|c|c|c|c|c|c|c|c|c|}
\hline \multirow[t]{3}{*}{ Process request } & checks if no library suggestion & 0.51 & 1.172 & 0.598 & checks if no library suggestion & 0.51 & 1.172 & 0.598 \\
\hline & retrieve missing info & 0.94 & 1.172 & 1.102 & retrieve missing info & 0.94 & 1.172 & 1.102 \\
\hline & additional approval & 0.94 & 1.172 & 1.102 & additional approval & 0.94 & 1.172 & 1.102 \\
\hline \multirow[t]{2}{*}{ Place order } & further investigations & 0.51 & 0.592 & 0.302 & further investigations & 0.51 & 0.592 & 0.302 \\
\hline & & & & & fill in additional info & 1.69 & 0.592 & 1.00 \\
\hline Process invoice & copy & 0.14 & 0.592 & 0.083 & copy & 0.14 & 0.592 & 0.083 \\
\hline \multirow[t]{2}{*}{ Close process } & additional information & 0.23 & 0.492 & 0.113 & additional information & 0.23 & 0.492 & 0.113 \\
\hline & Subtotal & & & 3.300 & & & & 4.300 \\
\hline TOTAL & & & & 8.743 & & & & 18.992 \\
\hline
\end{tabular}

${ }^{\mathrm{a}} 1.29=0.24+1.31,{ }^{\mathrm{b}} 1.55=0.24+1.31,{ }^{\mathrm{c}} 1.062=0.592$ (empl. B cat.) +0.47 (softw.), ${ }^{\mathrm{d}} 1.642=1.172$ (empl. A cat.) +0.47 (softw.), ${ }^{\mathrm{e}} 1.49=0.28+1.21$ 


\section{Table 6}

Total cost of acquisition of journals and the rest (excluding the notification activity costs)

\begin{tabular}{|c|c|c|c|c|c|c|c|c|}
\hline \multirow{2}{*}{\multicolumn{2}{|c|}{ STANDARD ACTIONS }} & \multicolumn{2}{|c|}{ Journals } & & & \multicolumn{3}{|c|}{ Rest } \\
\hline & & \multirow{2}{*}{$\begin{array}{l}\begin{array}{l}\mathbf{n}^{\circ} \text { of } \\
\text { minutes }\end{array} \\
0.94\end{array}$} & \multirow{2}{*}{$\begin{array}{l}\begin{array}{l}\text { cost }(€) / \\
\text { minute }\end{array} \\
1.172\end{array}$} & \multicolumn{2}{|c|}{$\begin{array}{l}\text { total cost } \\
\text { (€) }\end{array}$} & \multirow{2}{*}{$\begin{array}{l}\boldsymbol{n}^{\circ} \text { of } \\
\text { minutes }\end{array}$} & \multirow{2}{*}{$\begin{array}{l}\begin{array}{l}\text { cost }(€) / \\
\text { minute }\end{array} \\
1.172\end{array}$} & \multirow{2}{*}{$\begin{array}{l}\text { total cost } \\
(€)\end{array}$} \\
\hline Process request & process request & & & 1.102 & process request & & & \\
\hline & forward for order & 0.88 & 1.172 & 1.031 & forward for order & 0.88 & 1.172 & 1.031 \\
\hline \multirow[t]{2}{*}{ Place order } & place order & $1.86^{\mathrm{a}}$ & 0.592 & 1.101 & place order & $5.28^{\mathrm{b}}$ & 0.592 & 3.126 \\
\hline & $\operatorname{login}$ & 0.4 & 0.592 & 0.237 & & & & \\
\hline \multirow[t]{2}{*}{ Process invoice } & approve invoice & 0.49 & 1.172 & 0.574 & approve invoice & 0.49 & 1.172 & 0.574 \\
\hline & process invoice & $1.00^{\mathrm{c}}$ & 0.592 & 0.592 & process invoice & $1.56^{\mathrm{d}}$ & 0.592 & 0.924 \\
\hline Close process & close process & 1.47 & 0.492 & 0.723 & close process & 1.47 & 0.492 & 0.723 \\
\hline
\end{tabular}

\begin{tabular}{|c|c|c|c|c|c|c|c|c|}
\hline \multicolumn{9}{|c|}{ OPTIONAL ACTIONS } \\
\hline \multirow[t]{3}{*}{ Process request } & checks if no library suggestion & 0.51 & 1.172 & 0.598 & checks if no library suggestion & 0.51 & 1.172 & 0.598 \\
\hline & retrieval of missing information & 0.94 & 1.172 & 1.102 & retrieval of missing information & 0.94 & 1.172 & 1.102 \\
\hline & additional approval & 0.94 & 1.172 & 1.102 & additional approval & 0.94 & 1.172 & 1.102 \\
\hline Place order & further investigations & 0.51 & 0.592 & 0.302 & further investigations & 0.51 & 0.592 & 0.302 \\
\hline Process invoice & copy & 0.14 & 0.592 & 0.083 & copy & 0.14 & 0.592 & 0.083 \\
\hline \multirow[t]{2}{*}{ Close process } & additional information & 0.23 & 0.492 & 0.113 & additional information & 0.23 & 0.492 & 0.113 \\
\hline & Subtotal & & & 3.300 & & & & 3.300 \\
\hline TOTAL & & & & 8.660 & & & & 10.780 \\
\hline
\end{tabular}

${ }^{\mathrm{a}} 1.86=0.24+1.61,{ }^{\mathrm{b}} 5.28=0.24+5.04,{ }^{\mathrm{c}} 1.00=0.28+0.72,{ }^{\mathrm{d}} 1.56=0.28+1.28$ 
Figures

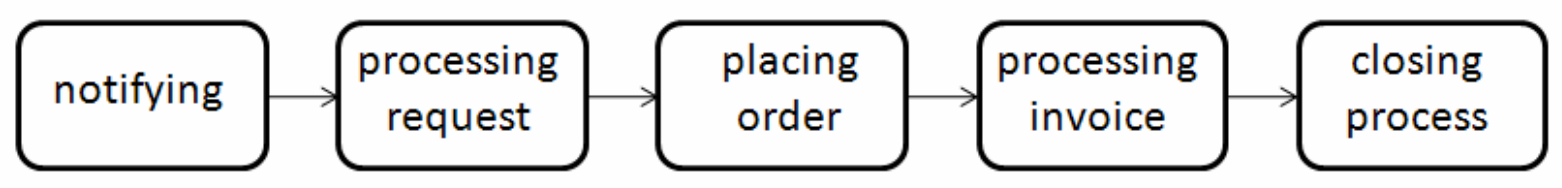

Figure 1 Activity flow of acquisition process in academic library 